\title{
ETTE TAZELİĞİN BELİRLENMESİ: YENİ YAKLAŞIMLAR
}

\section{Pelin Talu Özkaya*, Seval Dağbağlı, Semra Kayaardı}

Manisa Celal Bayar Üniversitesi Mühendislik Fakültesi Gıda Mühendisliği Bölümü, Muradiye, Manisa

Geliş / Received: 22.04.2021; Kabul / Accepted: 21.06.2021; Online bask1 / Published online: 17.07.2021

Talu Özkaya, P., Dağbağlı, S., Kayaardı, S. (2021). Ette tazeliğin belirlenmesi: Yeni yaklaşımlar. GIDA (2021) 46 (4) 1053-1067 doi: 10.15237/gida.GD21078.

Talu Ö₹kaya, P., Dağbağhl, S., Kayaard, S. (2021). Detection of meat freshness: New approaches. GIDA (2021) 46 (4) 1053-1067 doi: 10.15237/gida.GD21078.

ÖZ

Sağlıklı beslenme anlayışı ile taze ve kaliteli gıdaya ulaşma talebi son zamanlarda giderek artmaktadır. Gıdaların tazeliğini ve kalitesini yitirmeye başlamış olması, tüketici güvenini ve memnuniyetini sarsmakla kalmamakta, ürünün risk durumuna göre tüketicinin sağlığını da tehlikeye atmaktadır. Beslenmede akla ilk gelen temel gıda maddelerinden olan et gibi besleyici ve ekonomik değeri yüksek bir gidanın tazeliğinin belirlenmesinde zamanla yarış söz konusudur. Ne var ki, bu amaca yönelik klasik yöntemler fazla malzeme, işgücü ve zaman harcanan zorlu bir analiz sürecini beraberinde getirmekte, bu nedenle sözü geçen dezavantajların giderildiği alternatif yöntemlere ihtiyaç duyulmaktadır. Hatta tazelikteki değişimin izlenmesinde tüketicinin de dahil edildiği gerçek zamanlı tespitler mümkün hale getirilmeye çalsşılmaktadır. Bu derlemede, çeşitli et ve et ürünlerinin tazeliğini belirlemeye yönelik özellikle renk indikatörleri, sensörler ve biyosensörler gibi yeni yaklaşımlar ele alınmıştır.

Anahtar kelimeler: Et, tazelik, renk indikatörleri, sensör, biyosensör

\section{DETECTION OF MEAT FRESHNESS: NEW APPROACHES}

\begin{abstract}
Recently, there has been an increasing demand for fresh and high quality food as a result of healthy eating awareness. Depending on the risk status of the product, consumer health and safety get into danger as well as breaking consumer reliance and satisfaction due to the foods which have started to become unfresh and lose quality at the time of purchasing. Nutritious and economically valuable foods such as meat has been one of the major product groups which is needed to be checked for its freshness against time. However, classical methods require much labor and chemical usage as well as being time consuming. Therefore, there has been a need for alternative methods which can eliminate present disadvantages. Moreover, it is aimed to make possible real time detection of meat freshness including consumer based controls. This review evaluates new detection methods such as color indicators, sensors and biosensors to determine freshness of several kinds of meat.
\end{abstract}

Keywords: Meat, freshness, color indicators, sensor, biosensor.

\footnotetext{
* Yazışmalardan sorumlu yazar / Corresponding author

(1): pelin.ozkaya@cbu.edu.tr (1): (+90) 2362012013

且: (+90) 2362012020

Pelin Talu Özkaya; ORCID no: 0000-0001-6198-8313

Seval Dağbağlı; ORCID no: 0000-0001-9465-0116

Semra Kayaardı; ORCID no: 0000-0003-1747-0976
} 


\section{GİRİ̧̧}

G1dalarda tazelik, ürün bünyesindeki mikrobiyal gelişim, açığa çıkan metabolitler ve kimyasal değişimler doğrultusunda şekillenmekte olup bu kapsamda gidalardaki genel tazelik indikatörleri glukoz, organik asitler, etanol, uçucu azotlu bileşikler, ATP yıkımlanma ürünleri, karbondioksit, sülfürlü bileşikler, diasetil, amonyak, biyojen aminler, toksinler, enzimler gibi maddelerdir (Öksüztepe ve Beyazgül, 2015; Kocaman ve Sarımehmetoğlu, 2010; Purma ve Serdaroğlu, 2006). Tazelikte meydana gelen değişimlerin duyu organlarımız ile algılanacak hale gelmeden saptanması ise hem gida güvenilirliği ve tüketicinin korunmas1 hem de olas1 ekonomik kayıpların öngörülmesi/önlenmesi bakımından büyük önem taşımaktadır (Fu vd., 2019).

Et ve et ürünleri, temel besin unsurlar1 ve nem miktarı yüksek gidalar olarak bozulmaya son derece yatkın gidalar arasındadır. Bu gidaların depolanma süresince enzimatik ve/veya mikrobiyal kaynaklı oksidatif dönüşümler sonrasında protein, yağ ve karbonhidratlarının yıkımlanmasına bağlı olarak uçucu ve nahoş kokuya neden olan maddeler açığa çıkmaktadır (Jia vd., 2019). Etin tazeliği toplam uçucu bazik azot (Total Volatile Basic Nitrogen; TVB-N), hipoksantin/ksantin, biyojen aminler, hidrojen sülfür $\left(\mathrm{H}_{2} \mathrm{~S}\right), \mathrm{pH}$, mikrobiyolojik parametreler (toplam mezofilik aerobik canlı sayıs1) ile belirlenmektedir. $\mathrm{Bu}$ parametreler/maddeler, indikatör özellik gösteren unsurların başlıcaları olmakla beraber birbirleriyle de ilişkilidir (Fu vd., 2019). Örneğin, etin tazeliğini yitirmesi sürecinde meydana gelen kimyasal değişmelerin önemli bir bölümü mikrobiyolojik temellidir. Mikroorganizmaların proteolitik aktiviteleri sonucu serbest aminoasit zincirleri oluşmakta, bunlar da kolaylikla oksidatif deaminasyon, dekarboksilasyon ve desülfürizasyona uğrayarak $\mathrm{NH}_{3}, \mathrm{CO}_{2}$ ve $\mathrm{H}_{2} \mathrm{~S}$ oluşturmaktadır. Bunlardan, azotlu bileşiklerin yaygin formları arasında $\mathrm{NH}_{3}$, di- ve tri-metil amin bulunmakta olup bu gazların tamamı toplam uçucu bazik azot (TVB-N) olarak tanımlanmakta (Kuswandi ve Nurfawaidi, 2017) ve bu maddelerin konsantrasyonu arttıkça kademeli bir $\mathrm{pH}$ yükselmesi de söz konusu olmaktadır (Pacquit vd., 2006).
Diğer tazelik kriterlerinden biyojen aminler, gıdanın bünyesindeki spesifik aminoasitlerin, mikrobiyal yol ile dekarboksilasyonundan açı̆̆a çıkan düşük molekül ağırlıklı bileşikler olarak tanımlanmaktadır. Bu nedenle gidanın niteliği ve taşıdığı mikrobiyal yük, biyojen amin oluşumunda belirleyici sayllmaktadır (Lazaro vd., 2015). Biyojen aminler, bozulmanin ilerleyen safhalarında yüksek konsantrasyonlarda oluşmakta iken ette diğer tazelik indikatörleri olan hipoksantin veya ksantin ise hayvanın kesimini müteakip kaslarda birikmeye başlamaktadır (Albeda vd., 2017). Hipoksantin/ksantin ise, ATP yıkımlanma ürünlerindendir. ATP, önce inosin monofosfata (IMP) parçalanmakta, sonra da inosin ve hipoksantine y1kımlanmakta, oksidasyonun ilerlemesiyle ksantin ve son ürün olarak ürik asit oluşmaktadır (Karim vd., 2019). Ksantin/ hipoksantin tayinine yönelik çalışmalarla ilgili olarak literatüre bakıldığında Devi vd. (2013)'nin balık, tavuk, domuz ve sığır etinde ksantin tespiti için $\mathrm{Au}$ (altın) elektrodun $\mathrm{Ag}$ (gümüş) nanopartiküller/sistein ile modifikasyonundan elde ettiği amperometrik biyosensörü veya Albelda vd. (2017)'nin domuz eti için ksantin oksidaz ile grafen- $\mathrm{TiO}_{2}$ bazlı elektrokimyasal hipoksantin biyosensörü gibi çeşitli et ve et ürünleri için geliştirilen ve yeni yaklaşımlara örnek teşkil eden araştırmalar görülmekteyse de hipoksantin/ksantin tayinine yönelik olarak kırmızı ve beyaz etle yapilan araştırmaların, balık ve deniz ürünleri için yapılan çalışmalardan daha az olduğu dikkati çekmektedir. Balık ve deniz ürünlerinde tazeliğin saptanmasında uçucu azotlu bileşiklerin, genellikle bozulma sürecinin orta veya gec, evresi iç̧in belirleyici olduğu ifade edilirken, ATP yıkım ürünlerinin balık olür olmez oluşan ilk biyokimyasal ürünler olması nedeniyle bunların oluşum düzeyinin, bozulmanın erken aşamaları için daha aydınlatıcı olduğuna işaret edilmektedir (Saraç, 2011). Nitekim Metin vd. (2002) de alabalık burgerlerini 28 gün soğukta depolamışlar ve depolama boyunca üründeki değişimleri incelemişlerdir. Araştırmada duyusal değerlendirmelere ve hipoksantin düzeyine göre 21. gün itibariyle bozulma gerçekleştiği halde TVB-N değerlerinin düşuik kaldığı, $\mathrm{pH}$ değerlerinin de depolama süresince düşüş 
gösterdiği belirlenmiştir. Bu çalışmada olduğu gibi etin tazeliğini belirlemede uygun indikatörü bilmenin yanı sıra söz konusu indikatör maddenin tayin yöntemi de önemlidir. Çünkü tayin yöntemleri seçilirken bu yöntemlerin tespit limitleri, basit/kompleks olmas1 gibi faktörler dikkate alınmaktadır. Literatürde, tazelik indikatörlerinin belirlenmesine yönelik yapılan çalışmalarla pek çok teknik geliştirilmiştir. Bu derlemede, etin tazeliğinin belirlenmesinde kullanılan başlıca tayin yöntemlerinin yanı sıra özellikle bu konudaki yeni yaklaşımlar hakkında bilgiler verilmiştir.

\section{ETIIN TAZELİĞİNIN BELIIRLENMESİNDE KULLANILAN BAŞLICA TAYİN YÖNTEMLERİ}

Etin tazelik kriterlerinden herhangi birinin belirlenmesinde kromatografik, spektrofotometrik, titrimetrik yöntemlerin yanı sıra pH ölçümleri ve mikrobiyolojik analiz yöntemleri temel oluşturmaktadır. Titrimetrik yöntemde, iyi bir örnek homojenizasyonu, aranan maddenin ekstraksiyonu ve ekstraktın uygun kimyasallarla titrasyonundan elde edilen sarfiyatın kullanıldığı hesaplama ile sonuca ulaşılmaktadır. Nitekim Qiao vd., (2017), tavuk etinde TVB-N tespitini bu yöntemle yapmışlarsa da analiz süreci kapsamlı bir hazırlık gereksinimini beraberinde getirmektedir (Wojnowski vd., 2017). Öte yandan spektrofotometrik yöntem ile hipoksantin belirlenebilmekte (Albeda vd., 2017), pH ölçümü de etin kalitesini belirlemede yararlanılan kimyasal yöntemler arasında gösterilmekte (Kuswandi ve Nurfawaidi, 2017), fakat pH ölçümü her zaman doğru yönlendirmemekte veya tek başına yeterli olmamaktadır (Metin vd., 2002). Mikrobiyolojik yöntemler de ilgili standartlarda belirlenen şekilde uygulanarak (TS 6582-2 EN ISO 6888-2, TS 2664 gibi) tazeliğin seyri hakkında fikir vermekle beraber yine emek ve zaman kaybının söz konusu olduğu ifade edilmektedir (Wojnowski vd., 2017). Kromatografi, tazelik kriteri tespitinde kullanılan yöntemlerden bir diğeridir. Yüksek basınç sıv1 kromatografisi ile Şenman (2007), gökkuşagi alabalı̈̆nda biyojen aminlerin, Saraç (2011) ise Atatürk Baraj Golu'nden avlanan pullu sazan (Carasobarbus luteus) ve karaca (Capoeta trutta) balıklarında hipoksantinin miktarını belirlemişlerdir. Son yillarda ise var olan kromatografik yöntemler geliştirilerek türevlendirme işlemini hızlandıran ve örneklerden biyojen aminlerin ekstraksiyon verimini yükselten dispersif s1v1-s1v1 mikroekstraksiyon yöntemi ile kanatlı etleri, domuz eti ve biftek gibi çeşitli et örneklerinde GC-MS ile biyojen amin tespiti gerçekleştirilmiştir (Wojnowski vd., 2019).

Sonuç olarak, klasik yöntemler doğruluk ve geçerlilik bakımından yaygın olarak kullanılmakta ise de (Wu vd., 2019), özelikle kromatografik yöntemler için belirtilen maliyetli olma, nitelikli iş gücü gereksinimi ve fazla zaman almasi gibi dezavantajların yanı sira (Yazdanparast vd., 2019) titrimetrik yöntemlerde olduğu gibi kapsamlı bir örnek hazırlama (Wojnowski vd., 2017) ve analiz sürecinin (öğütme, filtrasyon, gerekli kimyasalların temini, titrasyon çözeltilerinin hazırlanması, titrasyon; Fishler, 1995) söz konusu olmas1, yeni yaklaşımlar arayışında temel oluşturmaktadır.

\section{ETIN TAZELİĞİNİ BELİRLEMEDE YENI YAKLAŞIMLAR}

Etin tazeliğinin belirlenmesinde kullanılan başlıca tayin yöntemlerinin işgücü, zaman ve kimyasal sarfiyatı gibi gereksinimleri azaltarak bu sürecin hızlandırılması hedeflenmektedir. Buna ek olarak, tüketici bazında da tazeliğin belirlenmesini mümkün kılacak daha ekonomik, pratik ve ayn1 zamanda hassas yeni yaklaşımlara yönelim dikkati çekmektedir (Wu vd., 2019). Bu yeni yaklaşımlar arasında sensörler (biyosensörler, yenilebilir sensörler; Zhai vd., 2020a) ve renk indikatörleri (Ezati vd., 2020) başta olmak üzere elektronik burun (Rajamaki vd., 2004), torimetre (Sujiwo vd., 2018), NIR-MIR (near- middle infared teknolojisi; Sinelli vd., 2010) gibi alternatif ölçüm cihazları ve teknikler yer almaktadır.

\section{Renk indikatörleri ve sensörler}

Akı1lı ambalajlama teknolojisinin dayandığ temeller arasında sensörler ve indikatörlerin olduğu ifade edilmekte (Zhai vd., 2019), bunlardan yararlanarak tazelik tespitinin tüketici bazında dahi yapılabilirliği mümkün görülmektedir. Tazeliğin yitirilmesine paralel olarak kolaylıkla fark edilecek bir görsel değişimin ortaya çıkması ile gerçek zamanlı bir izleme 
sağlanmakta, bu da sensör veya indikatörlerin ambalaj materyaline entegrasyonu ile gerçekleştirilmektedir. Sensörler ve renk indikatörleri, küçük farklar ile birbirinden ayrılmaktadır. Renk indikatörleri, ürünün durumuna göre çıplak gözle görülebilen renk değişimleri üzerinden kalitatif ve yar1-kantitatif tespit araçları (Zhai vd., 2019) olarak tanımlanmakta ve $\mathrm{pH}$ gibi değişimlere duyarlılık göstermekte iken, sensörler spesifik bir hedef maddeyi algilayıp kaydeden analitik cihazlar olarak (Deligöz vd., 2017) tanımlanmaktadır. Her ikisi de akıllı ambalajlama teknolojisinin ortak çatıs1 alında pek çok çalışmanın çıkış noktası olmuştur.

İndikatörler, bir gıdadaki kimyasal değişimi ve bu değişimin boyutunu, sahip olduğu spesifik özellikler doğrultusunda renk değiştirerek ortaya koyan maddelerdir. Bunlar, sentetik kimyasal indikatörler ve doğal kolorimetrik indikatörler olmak üzere temelde iki gruptur. Ayrıca, indikatör üretiminde yararlanılan tekniklere ve yeniliklere paralel olarak hassasiyeti arttırlan gelişmiş renk indikatörleri de bulunmaktadır (Wu vd., 2020). Ne var ki metil kırmızısı, kresol kırmızısı, bromkresol yeşili, bromkresol moru, klorofenol, bromtimol mavisi ve ksilenol gibi sentetik boyaların toksik ve hatta bazılarının karsinojenik olması, sağlığı ve çevreyi tehdit etme potansiyeli nedeniyle araştırıcıları doğal kaynakların kullanımına yöneltmektedir (Roy ve Rhim, 2020). Bu nedenle bitkiler ve köklü sebzeler başta olmak üzere çeşitli kaynaklardan elde edilen kurkumin, betanin, antosiyanin ve klorofil gibi doğal renk maddeleri, tazeliğin belirlenmesine yönelik çalışmalarda, özellikle $\mathrm{pH}$ değişimlerine hassasiyetleri nedeniyle kullanılan maddelerdir.

Günümüzde doğal kaynaklardan elde edilen indikatörlere olan yönelim, pek çok akıllı ambalaj çalışmasının çıkış noktasını oluşturmaktadır. Doğal renk maddeleri içerisinde antosiyaninlerin tazeliği belirlemeye yönelik çalışmalarda kullanılan başlica madde grubu olması, bozulmaya paralel olarak açığa çıan maddelere hassasiyetinin fazla olmasina dayandirilmaktadir. Yapilan kolorimetrik bir sensör çalışmasında kırmızı turp (Raphanus sativus L.) ve siyah pirinç (Oryza sativa $L$. indica) ekstraktlarından antosiyanin, ispanak
(Spinacia oleracea) ve kış yasemeni (Jasminum nudiflorum) ekstraktlarından ise klorofil ve karoten doğal pigmentleri elde edilmiştir. Bu pigmentler domuz etinde biyojen amin varlığını belirleme amacıyla kullanılmış ve domuz etinde mikrobiyal faaliyete bağlı oluşan biyojen amin varlığına en duyarlı pigmentin siyah pirinç ekstraktındaki antosiyaninler olduğu belirlenmiş olup bu performansin, analitler ile antosiyanin molekülünün hidroksil ve karbonil grupları arasındaki etkileşimden ileri geldiği öne sürülmüştür (Huang vd., 2014). Siyah pirinç kepeği antosiyaninleri yakın zamanda balık etinin tazeliğini belirleme amacıyla yapılan jelatin/okside kitin nanonkristalleri içerikli akıllı ambalaj çalışmasında da başarılı sonuç vermiştir (Ge vd., 2020). Çeşitli et ürünlerinin tazeliğini belirlemeye yönelik olarak yapılan başka çalışmalarda da, mor patates (Wei vd., 2017; Jiang vd., 2020; Chen vd., 2020a), mor domates (Li vd., 2021), dut (Zeng vd., 2019), Echium amoenum (Mohammadalinejhad vd., 2020), kırmız1 kabak (Vo vd., 2019; Liu vd., 2021; Chen vd., 2021), siyah havuç (Moradi vd., 2019), yabanmersini ve kırmızı üzüm kabuğu posası (Kürek vd., 2019), gül (Kang vd., 2019), bamya çiçeği (Zhai vd., 2017; Zhang vd., 2021) gibi çeşitli kaynaklardan elde edilen ve kolorimetrik özelliğinden başarılı biçimde yararlanılabilen antosiyaninler kullanılmışıtır.

Antosiyaninler ve diğer renk pigmentleri, ambalaj materyallerine entegre edilerek kullanılmaktadır. Yapısal ve kimyasal özellikleri dikkate alınarak amaca uygun seçilen doğal veya sentetik boya temelli bir indikatörün film haline getirilmesi bir dizi işlemle gerçekleştirilmektedir. Akıllı ambalajlamada kullanılan indikatör film üretimine ait çeşitli teknikler mevcuttur. Bir polimer/biyopolimer içerisine renk indikatörü ilave edilip dökme yöntemi (Roy ve Rhim, 2020) veya laminasyon tekniği ile film oluşturulduğu (Lee vd., 2020) çalışmalar, bu tekniklere örnek teşkil etmektedir. Bir başka çalışmada ise kurkuminin LDPE (düşük yoğunluklu polietilen) ile ekstrüde edilmesiyle kolorimetrik film elde edilirken (Zhai vd., 2020b), misır gluteni bazlı (zein) alizarin pigment çözeltisinden elektroeğirme tekniği ile nanosensör bazlı, $\mathrm{pH}$ 
indikatörü özelliğine sahip bir akıllı ambalaj üretilmiştir (Aghaei vd., 2020).

Balık eti için yapılan bir çalısmada, karboksi metil selüloz/nişasta kompozitine tatlı mor patateslerden elde edilen antosiyaninler entegre edilmiş ve özellikle amonyağın açığa çıkmasına bağlı olarak gerçekleşen $\mathrm{pH}$ değişimi rengin kırmızıdan mavi-yeşile dönmesiyle izlenmiştir (Jiang vd., 2020). Jelatin/polivinil alkol matrikse entegre edilmiş karadut ekstraktı antosiyaninleri ile de benzer bir çalışma yapılmış, uçucu azotlu bileşiklerin varlığında elde edilen indikatör film renginin parlak kırmızıdan koyu yeşile döndüğü belirlenmiştir (Zeng vd., 2019). Antosiyaninlerin temini daha önce de bahsedildiği gibi farklı kaynaklardan yapılabilmekte olup karideslerle yapılan bir çalışmada Echium amoenum antosiyaninleri, bakteriyel selüloz içerisinde immobilize edilerek $\mathrm{pH}$ değişimine duyarlı bir indikatör olarak kullanılmıştır (Mohammadalinejhad vd., 2020). Dilimlenmiş domuz etlerinin ambalajlanmasında kırmızı kabak antosiyaninleri, kitosan/polivinil alkol matriks içerisinde (Vo vd., 2019), yaban mersini ve kırmızı üzüm kabuğu posası ekstraktından elde edilen antosiyaninler ise kitosan ve karboksi metil selüloz matriks içerisinde (Kürek vd., 2019) kullanılmış ve tavuk etinin tazeliğinin belirlenmesinde başarılı olunmuştur. Antosiyaninler ile akıllı indikatör film yapımında kitosanın yanı sıra nişasta, jkarragenan, pullulan, agar, jelatin, vb. polisakkaritler ve çeşitli biyopolimer matriksler kullanılabilmektedir (Roy ve Rhim, 2020).

Kurkumin zerdeçaldan elde edilen, baharat ya da renk maddesi olarak kullanılan doğal bir renk indikatörü olup son zamanlarda antosiyaninlerin yanı sıra oldukça ilgi çekmekte ve eskiye göre daha fazla araştırmaya konu olmaktadır (Chen vd., 2020b). Balık ve deniz ürünlerinin tazeliğini belirlemeye yönelik olarak yapılan bir kolorimetrik film çalışmasında, kitosan/okside kitin nanokristallerinden oluşan matrikse entegre edilen kurkuminden yararlanılmışır (Wu vd., 2019). Aynı ürün grubu için uçucu aminlerin varlığına duyarlı olan kurkumin, polivinil prolidon (PVP) ve etil selüloz/polietilen oksit (PEO) polimer çözeltisine ilave edilmiş ve bu polimer ile elektroeğirme tekniği kullanılarak üretilen nanoliflerden farklı bir kolorimetrik indikatör elde edilmiş olup (Luo vd., 2020), kurkumin ve sülfür nanopartiküllerinin kullanıldığ pektin bazlı bir indikatör film çalışmasında, üretilen filmin karides ambalajlanmasında kullanımının uygun olduğu sonucuna varılmıştır (Ezati ve Rhim, 2020). Zhai vd. (2020b) ise ekstrüde LDPE-kurkuminden kolorimetrik film üreterek, sığır ve balık eti üzerinde TVB-N'e duyarlı bir akıllı ambalaj çalışması yapmışlar; özellikle de filmin bozulmaya paralel olarak açı sarıdan açık kahverengiye dönen amonyak sensörü olarak işlev gösterdiğini belirtmişlerdir. Zhang vd. (2021), tatlı su karidesleri (Macrobrachium rosenbergii) ile yaptığ 1 bir çalışmada agar ve polivinil alkol bazlı yapıya kurkumin ilavesiyle stabilitesi yüksek bir ambalaj elde etmişler ve ambalaj renginin, amonyak varlığında sarıdan kırmızıya döndüğünü bildirmişlerdir.

Alizarin, Türk kırmızısı olarak da anılmakta ve kökboyası bitkisinden elde edilen, alkolde çözünebilen bir renk maddesi olarak tanımlanmaktadır (Ezati vd., 2020). Yapılan bir çalışmada, selüloz/kitosan bazlı filmde kolorimetrik indikatör olarak alizarin kullanılmış ve bu filmin sığır eti kıymasındaki $\mathrm{pH}$ değişimini hassas biçimde belirleyebildiği görülmüştür (Ezati vd., 2019). Alizarin ve farklı selüloz çeşitleri ile kompozit yapı oluşturulduğu bir başka çalışmada da; bu kompozit yapının UV-görünür bölge özelliklerinin, radikalleri yakalama aktivitesinin ve 1sıl stabilitesinin geliştiği belirlenmiştir. Bu formdaki indikatör filmin, paketli et ürünlerinin ambalaj ortamındaki asidik veya bazik gaz oluşumuna bağlı $\mathrm{pH}$ değişimlerine oldukça duyarlı ve geri dönüşümlü renk geçişlerini mümkün kılan ( $\mathrm{pH}$ 2-12 arası sarıdan mora renk dönüşümü) iyi bir alternatif olduğu sonucuna varılmıştır (Ezati vd., 2020).

$\mathrm{pH}$ değişimlerine duyarlllı̆̆1 olan maddelerin kullanıldığ1 indikatör çalışmalarından biri de şikoninle yapılan ve domuz eti ile balık etinin paketlenmesine yönelik gerçekleştirilen bir araştırmadır (Ezati vd., 2021). Şikonin, bitkisel kaynakl1 (Lithospermum erytbrorbizon) bir farmasötik olup yara, yanik vb. tedavisinde kullanilan anti inflamatuvar, antibakteriyel, anti tümör, 
antioksidan vb. çeşitli fonksiyonlara sahip bir doğal naftokinon pigmentidir (Topçu ve Çölgeçen, 2015). Ezati vd. (2021) tarafindan yapılan bir çalışmada bu madde, selüloz tabaka üzerine adsorbe edilmek suretiyle indikatör film bünyesine alınarak ak1llı ambalaj üretiminde kullanılmıştır. Çalışmada, şikoninin selüloza çapraz bağlanmış olduğu FTIR ile görüntülenmiş, kağıt materyale bu maddenin entegrasyonu ile antioksidan aktivitenin, 1sıl stabilitenin ve suya dayanıklılığın arttığı görülmüştür. pH değişimine oldukça duyarlı ve stabil olduğu belirtilen filmin, ortam pH'sına bağlı olarak kırmızıdan maviye döndüğü ve bu sonuçlar nedeni ile akıllı ambalaj bünyesinde kullanılabilir olduğu bildirilmiştir.

Doğal pigmentlerin kaynak ve çeşitlerinin de zaman içerisinde çoğaltıldığ1 söylenebilir. Nitekim, spirulina bunlardan bir tanesidir. Spirulina, günümüzde g1da takviyesi olarak da piyasada varlık göstermekte olup $\mathrm{pH}$ hassasiyeti yüksek B-karoten, tokoferol, fikosiyanin, fikoeritrin ve klorofil pigmentleri bakımında zengin, karakteristik mavi-yeşil renkli bir mikroalg olarak tanımlanmaktadır (Lafarga vd., 2020). Spirulinadan mavi renkli fikosiyanin pigmentini elektroeğirme tekniği ile poli laktik asit (PLA) / (PEO) ultra ince nanoliflere entegre eden Moreira vd. (2018)'nin çalışması veya spirulinayı biyokütle (biyomas) halinde polimer nanolifler içerisine enkapsüle ederek kullanmak suretiyle kolorimetrik $\mathrm{pH}$ indikatörü üreten Kuntzler vd. (2020)'in çalışması, akı1lı ambalaj teknolojisi çerçevesinde iyi birer örnek teşkil etmektedir.

Doğal veya sentetik indikatörlerin dünya çapında yaygınlaştı̆̆1 söylenemese de ticari boyuta ulaşabilmiş olan az sayıdaki örneği göz ard1 etmemek gerekir. Kırmızı et ve kanatlı etlerinde $\mathrm{pH}$ değişimi ve biyojen aminlerin varlığına duyarlı antosiyanin bazlı indikatörler ile üretilen sensörler, deniz ürünlerinde uçucu aminlerin varlığına duyarlı tazelik indikatörü ve ambalajı kanatlı etleri için üretilen hidrojen sülfür varllğına duyarlı indikatörler ticari olarak kullanılmaktadır (Ahmed vd., 2018).

Tazelik kriterlerini belirlemede kullanılan bir başka yaklaşım olan sensörler ise gelecegin akıllı paketleme sistemleri için en umut verici ve yenilikçi teknoloji olarak kabul edilmektedir (Takma ve Nadeem, 2019). Literatür incelendiğinde, çeşitli et ve et ürünleri için geliştirilmiş ve farklı materyallerin kullanıldığı pek çok sensör çalışması bulunmaktadır. Metal nanopartiküllerin çeşitli matrikslere hapsedilmesiyle üretilen kolorimetrik sensörler, bu alandaki uygulamaların dikkat çeken bir bölümünü oluşturmaktadır. Tavuk etinde gerçek zamanlı bir izleme için gümüş (Ag) nanopartiküllerin kullanıldığı gellan gam bazlı kolorimetrik hidrojen sülfür sensörü (Zhai vd., 2019) bunlardan biridir. Zhai vd., (2020a)'nin çalışmasında, agar (AG), antosiyanin (AN), gellan gam (GG) ve $\mathrm{TiO}_{2}$ nanopartiküllerinden çift katmanlı filmler halinde ürettikleri sensörler karșılaştırılmıștır. AG/GG, AG-AN/GG, AGAN/GG- $\% 0.5 \mathrm{TiO}_{2}, \mathrm{AG}-\mathrm{AN} / \mathrm{GG}-\% 1 \mathrm{TiO}_{2}$ ve AG-AN/GG- $\% 2 \quad \mathrm{TiO}_{2}$ olan kombinasyonlar içerisinde gerek kolorimetrik özellikler bakımından stabilitesi gerekse bazik gazlara (amin) duyarll11k bakımından AG-AN/GG-\%2 $\mathrm{TiO}_{2}$ bileşiminin en başarılı kombinasyon olduğu belirlenmiștir.

Öte yandan, etin tazeliğini belirlemeye yönelik optik temelli bir sensör çalışmasında, silikon matrikse pH indikatörü özellikli iyon çifti (lipofilik iyon çifti: anyon karakterli $\mathrm{pH}$ indikatörü ve kuaterner amonyum katyonu, silikon elastomerin iç katmanına homojen dağıtılarak) immobilize edilerek yapilan ve özellikle amonyağa duyarlılık gösteren ambalaj ortamındaki gazların asidikbazik karakterindeki değişim belirlenerek ette tazeliğin seyri gözlenmeye çalışılmıştır (Werner vd., 1995).

Mikrobiyolojik durumun incelenmesine yönelik olarak geliştirilen sensörler de var olmakla beraber, bu çalısmaların önemli bir bölümü patojenler ve toksinlerini tespit etme amaçlı olduğundan, tazeliğin izlenmesine yönelik tasarımlar az sayıdadır. Zohora vd. (2013), elektronik burun cihazına kalay sensörü entegre ederek etlerdeki mikrobiyolojik kontaminasyonun belirlenmesini sağlayan tasarım ile bakteriyel yükün \%98 oranında tespitini sağlamışlardır. Mercan balığında mezofilik bakteriler ve Enterobacteriaceae tespitine yönelik olarak 
geliştirilen kolorimetrik sensör (Zaragoza vd., 2013) de tazeliği belirleme odaklı çalısmalar arasındadır.

Doğal renk indikatörlerinde ifade edildiği gibi tüketiciye güven veren antosiyanin, kurkumin gibi pek çok meyve, sebze ve çiçeklerin görünür bölgedeki doğal boyar maddeleri yenilebilir sensörler kapsamında da değerlendirilmektedir (Halonen vd., 2020). Kolorimetrik tespit gerçekleştirmek için Dudnyk vd., (2018)'nin çalışmasında kırmızı kabaktan elde edilen ve antosiyanin içeren ekstrakta pektin ilavesiyle oluşturulan film, ambalaj materyaline entegre edilmiştir. Sığır eti, tavuk eti, balık eti, karides gibi farklı et çeşitlerinin tazeliğini yitirmesiyle tepe boşluğundaki miktarı giderek artan aminlerin varllğ1, bu filmin renginin mordan sariya dönmesiyle belirlenmiştir. Ian vd., (2020) ise aminlerle etkileşime giren ve meyve ekstraktlarında doğal olarak bulunan genipin maddesini, biyojen amin varllğını tespit etmek üzere yenilebilir Ca-aljinata immobilize ederek tavuk etinin tazeliğini belirlemek amacıyla kullanmıslardır. Elde edilen kolorimetrik sensördeki genipin, soğukta $\left(4^{\circ} \mathrm{C}\right)$ muhafaza edilen örneklerde putresin, kadaverin, tiramin ve histaminle reaksiyon vererek koyu maviye dönüşmektedir.

Et ve et ürünlerinin tazeliğini belirlemeye yönelik sensör ve indikatör çalışmalarının tamamı; hızlı, güvenilir, ürün durumundaki değişimi kolaylıkla fark edilir hale getiren, zararsiz ve ekonomik bir ambalaj oluşturma çabasında birleşmektedir. Bir yandan da bu teknolojinin hammaddesi olan renk maddelerinden özellikle doğal kaynaklı olanlarının mümkün olabildiğince stabil kalması, beklenen işlevi göstermeleri açısından önem taşımakta olup her bir maddenin farklı dış etkenlerden farklı ölçüde etkilendiği bilinmektedir. Örneğin kurkumin 1şığa duyarlı iken betanin ve antosiyanin 1sıya duyarlılık göstermektedir (Etxabide vd., 2021).

Sonuç olarak, akıllı ambalajlar geliştirilirken bu maddelerin tutunacağ1 uygun matriksler oluşturularak en iyi performansa sahip filmler üretilmeye çalışlmaktadır. Zhai vd. (2019)'nin, tavuk ve balık etinin akıllı ambalajlanmasinda kullandığı hidrojen sülfür sensörünün belirginliği, $4^{\circ} \mathrm{C} / 8$ günlük depolama sürecinde tüketicinin çıplak gözle fark edebileceği şekilde azalmaktadır. Alizadeh-Sani vd., (2020)'nin kuzu etiyle yaptıkları akıllı ambalaj çalışmasında, antosiyanin içerikli indikatör katman, ürünün tazeliğini yitirmesine paralel olarak koyu kırmızı görünümden soluk şeftali bir tona dönmektedir. Ezati ve Rhim (2020)'nin karideslerle yapmış olduğu çalışmasında ise depolama başlangıcında tekdüze renge sahip olan kurkumin içerikli filmin orta kısmı, 36. saatte koyulaşarak tazelik değişiminin algılanmasını sağlamıştır.

Tüm bu çalışmalardan ayrıca, tüketici beklentilerine sağlık ve çevre duyarlilığının da eklenmesiyle doğal pigmentlerin yanı sıra biyobozunur polimerlerle yapılan çalş̧malar da literatürde yer bulmaya başlamışır. Nitekim Latos-Brozio ve Masek (2020)'nin çalışmasında, klorofil, kurkumin, lutein ve karoten gibi doğal renklendiriciler ile yenilenebilir ve biyobozunur özellik taşıyan polimer matriksleri (polilaktid ve polihidroksibütirat) kullanarak ürettikleri ambalaj malzemesinin alternatif olabileceği öne sürülmüştür. Söz konusu çalışmada, ambalaj malzemesinin 1sıl ve mekanik özelliklerinin de gelişerek ısıl oksidasyon, UV ve havanın etkisiyle de renk değişimlerinin meydana geldiği, böylece ambalaja yönelik klasik beklentilerin ötesinde çevre dostu ve çok fonksiyonlu bir üretim gerçekleştiği ifade edilmiştir. Söz konusu çalışmalar, umut vadeden yönleri ve sağlayacağı avantajlara karşı birtakım dezavantajlar veya geliştirilmesi gereken yönleri de içermektedir. Nitekim, akıllı ambalaj bünyesinde kullanılacak olan maddenin stabilite sorunları ve maliyete etkisi dikkati çekmektedir. Ayrıca, ambalajın içerisinde kullanılan malzemelerin ürün bileșimi ve duyusal özellikler üzerine etkisi, sağlık üzerindeki potansiyel etkileri ve aynı zamanda yasal düzenlemelerdeki yeri gibi unsurların tam anlamiyla belirlenmesi gerekmektedir (Takma ve Nadeem, 2019).

\section{Biyosensörler}

Biyosensörler, sensörlerden farklı olarak biyolojik algilama birimine sahiptir. Biyosensörler, biyolojik 
tanıma elemanı ile analiz edilecek olan hedef molekuilün etkileșime girmesi sonucu olușan biyokimyasal yanıtı, olçulebilir fiziksel bir sinyal haline dönüs,türen küç,ik algılayıcı cihazlar olarak tanımlanmaktadır (Kivrak, 2019). Etin tazelik kriterlerinden olan hipoksantin / ksantin (Reza vd., 2014), biyojen amin (Verma vd., 2019), kreatin (Fazial vd., 2018) gibi maddelerin analizi amacıyla biyosensör teknolojisinden yararlanılmış olan pek çok çalışma bulunmaktadır. $\mathrm{Bu}$ çalışmalar içerisinde analit olarak özellikle hipoksantin ve ksantinin seçildiği tasarımlara sıklıkla rastlanmaktadır. Nitekim Albelda vd. (2017)'nin çalışması, domuz etine yönelik olarak ksantin oksidaz ile grafen- $\mathrm{TiO}_{2}$ bazlı elektrokimyasal hipoksantin biyosensörü örneklerinden biri olup biyosensör tasarımlarının farklı tasarımlar ve malzemelerle çeşitlendirilmesi de mümkündür. Bunlardan, Chen vd. (2017)'nin geliştirdiği renk dönüşümlü (multicolor) biyosensör, çıplak gözle algilanabilecek bir reaksiyon mekanizmasına göre tasarlanmıştır. Kullanılan altın nano çubuk yüzeyleri (GNR:

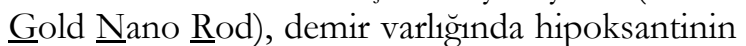
oksidasyonuyla açığa çıkan hidrojen peroksitin etkisiyle renk değişimi olarak algilanacak bir plazmon rezonans (SPR) değişimine girmektedir.

Bir başka yüzey plazmon rezonans (SPR) bazlı biyosensör örneği de Tantalum (v) oksit $\left(\mathrm{Ta}_{2} \mathrm{O}_{5}\right)$ nano-yapıları içerisinde ksantin oksidaz enziminin hapsedilmesiyle elde edilen fiberoptik ksantin biyosensörüdür (Kant vd., 2018). Donuk deniz ürünleri için geliştirilmiş olan, ksantin oksidazın bakır bazlı metal-organik yapida nanolif film üzerine immobilize edilmesiyle elde edilen elektrokimyasal nanosensörler (Wang vd., 2019) de son yıllarda geliştirilen tasarımlara örnek teşkil etmektedir. Yazdanparast vd. (2019)'1n, poli (Laspartik asit)/çok katmanlı karbon nanotüp modifiyeli camsı karbon elektroda immobilize ettikleri ksantin oksidaz enzimini içeren biyosensör tasarımı da, balık etinde ksantin tespiti için başarılı olmuştur. Chen vd. (2019) ise daha geniş bir ürün grubu olarak su ürünleri için platin nanopartiküller ile geliştirdiği biyosensör ile hipoksantinin tespitinde hızlı sonuç alınmasını mümkün kilmıştır. Mustafa vd. (2021) ise, geliştirdikleri seryum oksit bazlı hipoksantin biyosensörü ile daha düşük maliyet, pratik kullanım ve analiz performansında artış gibi kazanımlar elde ederek aktif kullanıma uygun yeni jenerasyon bir tasarımın öncüsü olmuşlardır.

Her ne kadar hipoksantin ve ksantin analizine yönelik biyosensör çalışmaları fazla olsa da, literatürde diğer tazelik kriterlerini tespit edebilen biyosensör çalışmaları da mevcuttur. Bunlar içerisinde biyojen aminlerin tespitine yönelik geliştirilen enzim biyosensörleri bulunmakta olup bu biyosensörlerin tasarımında amin oksidaz, transglutaminaz, diamin oksidaz, putresin oksidaz gibi enzimler kullanılarak üretilen elektrokimyasal biyosensörler mevcuttur (Park vd., 2015; Verma vd., 2019). Hatta, bu biyosensörlerin biyojen amin tespitini laboratuvar ölçekli bir analiz olmaktan ç1kararak saha testi konumuna getirebileceği ön görülmektedir (Verma vd., 2019). Nitekim Vanegas vd. (2018), fermente edilmiş ve edilmemiş balık eti ezmelerinin de (fish paste) dahil olduğu gida ürünleri için geliştirdikleri tasarımda, diamin oksidaz enzimini kullandıkları elektrokimyasal biyosensör ile biyojen amin tespitini başarıyla gerçekleştirmişlerdir. Buna karşıı, her biyosensör çalışmasının beklenen performansı sağlayamadığını belirtmek de yerinde olacaktır. Örneğin, bir kemilüminesans (kimyasal 1şıma) biyosensör çalışmasında biyojen amin tespiti, enzimatik (putresin/diamin oksidaz) etkileşime dayanmakta olup sığır, domuz, tavuk, hindi ve balık olmak üzere beş ayrı et örneği ile çalışılmış ancak örneklerin ön hazırllğına ilişkin veya biyosensörün girişim yapmaması yönünde ek çalışmalara ihtiyaç olduğu belirtilmiştir (Miklicanin ve Valzacchi, 2017).

Tazeliğin belirlenmesinde farklı hedef moleküllerin de baz alındığı çalışmalar bulunmaktadır. Domuz etinde tazeliği belirlemeye yönelik yapılan bir çalışmada, glukoz hedef molekül olarak alınmış ve modifiye altın elektroda poliglutamat-glukoz oksidaz kompleksi kaplanmak suretiyle bir biyosensör üretilmiştir (Ahmed vd., 2018). Balık etinde tazeliğin tespit edilmesi amaciyla hedef molekülün kreatin olduğu bir diğer çalışmada ise biyolojik ajan olarak kreatinaz ve üreaz olmak üzere iki enzimden yararlanılmış ve reflektans ölçümüne dayalı bir 
optik kreatin biyosensörü elde edilmiştir (Fazial vd., 2018).

Gerek sinyal dönüştürücü gerekse elektrot tasarımındaki farklıliklarla aynı veya farklı analitleri tespit etmeye yönelik, farklı performans Özelliklerine sahip çok çeşitli biyosensör çalışması yapilabilmekte iken bunlardan bazıları tek bir et çeşidi, bazıları da birden fazla et çeşidi için kullanılabilir niteliktedir. Her tasarımın kendi içerisindeki güçlü ve zayıf yönleri irdelenerek gelinen noktanın ileriye taşınması ve analiz sürecinin kolaylaştırılmasına çalışılmaktadır.

Ambalajlı et ürünleri için ticari ölçekte kullanımı olan biyosensörler mevcuttur; ancak bunlar, patojen varlığını tespit amaçlı kullanılanlardır. Bu biyosensörlerde, ambalaja entegreli bir barkod membranına patojen antikoru fikse edilmekte ve ilgili patojenin varlığına bağlı olarak barkodun okunabilirliği azalmakta, yani barkod silinmeye başlamaktadır (Ahmed vd., 2018). Esasen patojen kontaminasyonun tazelik kavramı ile doğrudan bağlantısı olmadığı için bu yöndeki çalışmalar detaylandırılmamıştır. $\mathrm{Ne}$ var ki, tazeliğin belirlenmesine yönelik olarak gelinen noktada biyosensörlerin tam anlamıla yaygınlaştığ1 söylenememektedir. Biyosensör çalışmalarında maliyetli denemeler ve üretilecek biyosensörün işlevsellik bakımından minyatürize edilme gerekliliği, uygun destek materyalinin seçimi ve biyoajanın immobilizasyonundaki zorluklar, seçicilik ve tespit limitinin (LOD) her biyosensörde beklentileri karşılamaması gibi sorunlar mevcuttur (Asal vd., 2018). Ayrıca çoklu analit ölçümleme gibi kesinlik ve güvenilirliği artıran çalışmalara ihtiyaç duyulmaktadır. Bu da, bozulmanın erken aşamalarını saptamak açısından önem taşımakta, tazeliğin yitirilmeye başlandığ1 fakat ürünün tüketime uygunsuz hale gelmediği evrenin de belirlenmesini mümkün kilacaktır (Ghasemi-Varnamkhasti vd., 2018).

\section{Diğer Yeni Yaklaşımlar}

Etin tazeliğinin belirlenmesine yönelik yeni yaklaşımlar, ürün içeriğindeki bakteri sayısı ve duyusal özelliklerin irdelenmesini temel alan alternatif teknikleri de içermektedir. $\mathrm{Bu}$ tekniklerden başlıcaları elektronik dil/burun, torimetre gibi ölçüm cihazları, NIR veya MIR
(Near veya Middle Infrared) tekniği, hiperspektral görüntüleme olarak sıralanabilir. Bunlar içerisinde elektronik burun, depolama süresince etten salınan uçucu bileşenlerin ölçümlenmesine dayanmaktadır. NIR veya MIR ise spektroskopik verilerin temel bileşen analizine dayalı iken hiperspektral görüntüleme, canlı bakteri dağılımının nicel olarak analiz edildiği bir tekniktir. Son olarak torimetre; hassas, portatif ve kullanımı kolay bir enstrüman olup hayvansal dokulardaki elektriksel özelliklerin değişimini ölçmek suretiyle etin tazeliğini belirlemede başarıyla kullanılmaktadır (Sujiwo vd., 2019). Literatürde bu yöntemler kullanılarak farklı et çeşitleri ile yapılan çalışmalar mevcuttur. Örneğin, taze ton balığı, vakum ambalajlı sı̆̆ır eti (Dobrucka ve Cierpiszewski 2014) ve modifiye atmosferle paketlenen tavuk eti parçalarının (Rajamaki vd., 2004) kalitesinin, elektronik burun sistemi ile başarılı şekilde tespit edildiği bildirilmiştir. NIR ve MIR tekniğinin kullanıldığ1 bir başka çalışmada da, yüksek oksijen içerikli modifiye atmosfer ile paketlenen $\left(\% 30 \mathrm{CO}_{2}\right.$ ve $\% 70 \mathrm{O}_{2}$ ) dana kıyması örneklerinin kalitesindeki değişim, bilgisayar skorlarının zamana karşı modellemesinden elde edilen depolama süresi/sıcaklık çıtılarıyla sinıflandırılmışıtır (Sinelli vd., 2010). Tavuk etinin tazeliğini belirlemeye yönelik olarak yapılan bir çalışmada ise uçucu bazik azot miktarı ve mikrobiyal sayının torimetre değerleri ile paralellik gösterdiği ortaya konmuştur (Sujiwo vd., 2018). Örnekleri çoğaltmak mümkün olmakla beraber, bu kapsamda yapılan çalışmaların başarısı değerlendirildiğinde, söz konusu yeni yaklaşımların belli bir noktaya ulaştı̆̆ görülmektedir. Buna karşılık, diğer pratik yöntemlerin aksine bu yaklaşımların tüketiciye ulaşma ve hatta tüketim anına dek tazeliğin izlenmesini sağlama gibi bir iddiaya sahip olmadığı, saha ya da laboratuvar ölçekli tespitlerin yapılmasında yararlı olacağı öngörülmektedir.

\section{SONUÇ}

Son yıllarda artış gösteren tazelik sorunları ve gida zehirlenmeleri gündemde önemli bir yer bulmaktadır. Ayrıca et gibi besleyici ve ekonomik değeri yüksek bir gıdanın tazeliğinin en hızl, kolay ve doğru şekilde belirlenmesi, olası kayıp ve 
zararların öngörülmesi ve önlenmesi bakımından önem taşımaktadır.

Titrimetrik, spektrofotometrik, kromatografik, mikrobiyolojik yöntemler gibi geleneksel yöntemlerde karşılaşılan zorlukların giderilmesi ve evsel/tüketici düzeyindeki tespitlerin mümkün kılınması adına yapılan araştırmalarda sensörler ve indikatörlerin başı çektiği yeni teknolojilere yönelim gerçekleşmekte, geliştirilen sistemler ambalaja entegre edilerek tüketiciyle buluşturulmaya çalışılmaktadır. $\mathrm{Bu}$ yöndeki çalışmalarda, tazelik değişiminin çıplak gözle fark edilecek şekilde belirgin ve gerçek zamanlı olarak ortaya çıkarılmasına yönelik pek çok başarılı örnek mevcuttur. Bunun yanı sıra biyosensörler, tazelik kriteri olarak seçilen herhangi bir analiti hassasiyetle algilayan analitik cihazlar olarak son zamanlarda önemli bir alternatif haline gelmiş ve tasarımsal farklılıklarla bu cihazların performansı oldukça arttırılmıştır. Öte yandan giderek artan sağlık bilinci ve doğal kaynaklardan elde edilen materyallerin tüketiciye güven vermesi yönüyle yenilebilir sensörler ve farklı çalışma prensipleri ile son yıllarda öne çıkan NIR \& MIR, torimetre, elektronik burun gibi alternatif cihazlar da öne çıkmaktadır.

Çalışılan her yeni yaklaşımda, tazelik kriterinin kolayca tespit edilmesi ve analiz sürecinin kolaylaştırılmasının yanı sıra tüketicinin de tazeliği kolayca anlayabileceği ambalajların geliştirilmesine çalışılmaktadır. Akıllı ambalajlama teknolojisiyle özdeşleşen bu yeniliklerin, ürüne dair gerçek zamanlı bir gözlem sağlamak ve tüketici güvenini pekiştirmek gibi getirileri olsa da ak1lli ambalajlama uygulamalarının çeşitli nedenlerle ülkemiz de dahil olmak üzere dünya genelinde beklenen ticari boyuta geçememiş olduğu görülmektedir. Hatta, et ve et ürünleri için olabildiğince hızlandırılması istenen tazelik tespit sürecinde, çeşitli dezavantajlarına rağmen klasik yöntemlere başvurulmakta, yeni yaklaşımların daha tercih edilir konuma geçmesi adına yol katedilmesi gerektiği ve bu nedenle gelişmeye açık olduğu görülmektedir.

\section{ÇIKAR ÇATIŞMASI BEYANI}

Yazarların, başka kişiler ve/veya kurumlar ile çıkar çatışması bulunmamaktadır.

\section{YAZAR KATKILARI}

PTÖ literatürü taradı ve SD ile beraber yazdı. SK makalenin son halini okudu ve onayladi.

\section{KAYNAKLAR}

Aghaei, Z., Ghorani, B., Emadzadeh, B., Kadkhodaee, R., Tucker, N. (2020). Proteinbased halochromic electrospun nanosensor for monitoring trout fish freshness. Food Control (111): 107065.

Ahmed, I., Lin, H., Zou, L., Li, Z., Brody, A. L., Qazi, I., M., Lv, L., Pavase, T. R., Khan, M. U., Khan, S., Sun, L. (2018). An overview of smart packaging technologies for monitoring safety and quality of meat and meat products. Packag Tech Sci (31):449-471. doi: 10.1002/pts.2380.

Albeda, J. A. V., Uzunoğlu, A., Santos, G. N. C., Stanciu, L. A. (2017). Graphene-titanium dioxide nanocomposite based hypoxanthine sensor for assessment of meat freshness. Biosens Bioelectron (89): 518-524.

Alizadeh-Sani, M., Tavassoli, M., Mohammadian, E., Ehsani, A., Khaniki, G. J., Priyadarshi, R., Rhim, J-W. (2020). pH-responsive color indicator films based on methylcellulose/chitosan nanofiber and barberry anthocyanins for real-time monitoring of meat freshness. Int J Biol Macromol S0141-8130(20)34871-6. https://doi.org/ 10.1016/j.ijbiomac.2020.10.231.

Asal, M., Özen, Ö., Şahinler, M., Baysal, H. T., Polatoğlu, İ. (2018). An overview of biomolecules, immobilization methods and support materials of biosensors. Sensor Rev, https://doi.org/10.1108/SR-04-2018-0084

Chen, Z., Lin, Y., Ma, X., Guo, L., Qiu, B., Chen, G., Lin, Z. (2017). Multicolor biosensor for fish freshness assessment with the naked eye. Sensor Actuat B-Chem (252): 201-208.

Chen, S., Wu, M., Lu, P., Gao, L., Yan, S., Wang, S. (2020a). Development of $\mathrm{pH}$ indicator and antimicrobial cellulose nanofibre packaging film based on purple sweet potato anthocyanin and oregano essential oil. Int J Biol Macromol (149): 271280.

Chen, M., Yan, T., Huang, J., Zhou, Y., Hu, Y. (2021). Fabrication of halochromic smart films by 
immobilizing red cabbage anthocyanins into chitosan/oxidized-chitin nanocrystals composites for real-time hairtail and shrimp freshness monitoring. Int J Biol Macromol (179): 90-100.

Chen, J., Yu, L., Yan, F., Wu, Y., Huang, D., Weng, Z. (2019). A fluorescent biosensor based on catalytic activity of platinum nanoparticles for freshness evaluation of aquatic products. Food Chem (310): 125922.

Chen, H., Zhang, M., Bhandari, B., Yang, C. (2020b). Novel pH-sensitive films containing curcumin and anthocyanins to monitor fish freshness. Food Hydrocoll (100): 105438.

Deligöz, E., Bilge, N. (2017). Sütle Gelen Tehdit: Aflatoksin M1. Turjaf 5 (8): 846-857.

Devi, R., Batra, B., Suman, L., Yadav, S. (2013). A method for determination of xanthine in meat by amperometric biosensor based on silver nanoparticles/cysteine modified Au electrode. Process Biochem, 48(2): 242-249.

Dobrucka, R., Cierpiszewski, R. (2014). Active and Intelligent Packaging Food Research and Development- A Review. Pol J Food Nutr Sci, 64(1): 7-15.

Dudnyk, I., Janecek, E. R., Joset, J. V., Stellacci, F. (2018). Edible sensors for meat and seafood freshness. Sensor Actuat B-Chem (259): 1108-1112.

Etxabide, A., Kilmartin, P. A., Mate, J. I. (2021). Color stability and pH-indicator ability of curcumin, anthocyanin and betanin containing colorants under different storage conditions for intelligent packaging development. Food Control (121): 107645.

Ezati, P., Bang, Y., Rhim, J-W. (2021). Preparation of a shikonin-based $\mathrm{pH}$-sensitive color indicator for monitoring the freshness of fish and pork. Food Chem (337): 127995.

Ezati, P., Rhim, J-W. (2020). pH-responsive pectin-based multifunctional films incorporated with curcumin and sulfur nanoparticles. Carbobyd Polym (230): 115638.

Ezati, P., Rhim, J-W., Moradi, M., Tajik, H., Molaei, R. (2020). CMC and CNF-based alizarin incorporated reversible $\mathrm{pH}$-responsive color $\mathrm{T}$ indicator films. Carbohyd Polym (246): 116614.

Ezati, P., Tajik, H., Moradi, M. (2019). Fabrication and characterization of alizarin colorimetric indicator based on cellulose-chitosan to monitor the freshness of minced beef. Sensor Actuat B-Chem (285): 519-528.

Fazial, F. F., Tan, L. L., Zubairi, S. I. (2018). Bienzymatic creatine biosensor based on reflectance measurement for real-time monitoring of fish freshness. Sensor Actuat B-Chem (269): 3645.

Fisher, F. (1995). Commission decision of 8 March 1995, fixing the total volatile basic nitrogen (TVB-N) limit values for certain categories of fishery products and specifying the analysis methods to be used. Official Journal of the European Communities. Retrieved from http://data.europa.eu/eli/dec/1995/149/oj.

Fu, L., Wang, A., Zhang, H., Zhou, Q., Chen, F., Su, W., Yu, A., Ji, Z., Liu, Q. (2019). Analysis of chicken breast meat freshness with an electrochemical approach. J. Electroanal. Chem (855): 113622

Ge, Y., Li, Y., Bai, Y., Yuan, C., Wu, C., Hu, Y. (2020). Intelligent gelatin/oxidized chitin nanocrystals nanocomposite films containing black rice bran anthocyanins for fish freshness monitorings. Int J Biol Macromol (155): 1296-1306.

Gahasemi-Varnamkhasti, M., Apetrei, C., Lozano, J., Anyogu, A. (2018). Potential use of electronic noses, electronic tongues and biosensors asmultisensor systems for spoilage examination in foods. Trends Food Sci Technol (80): 71-92.

Halonen, N., Pálvolgyi, P. S., Bassani, A., Fiorentini, C., Nair, R., Spigno, G., Kordas, K. (2020). Bio-Based Smart Materials for Food Packaging and Sensors - A Review. Bio-Based Smart Material (7) article 82 doi: 10.3389/fmats.2020.00082.

Huang X.W., Zou X.B., Shi J.Y. (2014). Determination of pork spoilage by colorimetric gas sensor array based on natural pigments. Food Chem (145): 549-554. 
Ian, M., Fiona, J., Christopher B., C. (2020). An edible genipin-based sensor for biogenic amine detection. J Chem Tech Biotechnol, https://doi.org/jctb.6556

Jia, S., Li, Y., Zhuang, S., Sun, X., Zhang, L., Shi, J., Hong, H., Luo, Y. (2019). Biochemical changes induced by dominant bacteria in chill-stored silver carp (Hypophthalmichthys molitrix) and GC-IMS identification of volatile organic compounds. Food Microbiol Dec. (84): $103248 . \quad$ doi: 10.1016/j.fm.2019.103248.

Jiang, G., Hou, X., Zeng, X., Zhang, C., Wu, H., Shen, G., Li, S., Luo, Q., Li, M., Liu, X., Chen, A., Wang, Z., Zhang, Z. (2020). Preparation and characterization of indicator films from carboxymethyl-cellulose/starch and purple sweet potato (Ipomoea batatas (L.) lam) anthocyanins for monitoring fish freshness. Int J Biol Macromol (143): 359-372.

Karim, N, U., Kennedy, J. T., Linton, M., Patterson, M.,Watson, S., Gault, N. (2019). Determination of nucleotide and enzyme degradation in haddock (Melanogrammus aeglefinus) and herring (Clupea harengus) after high pressure processing. PeerJ (7): e7527 doi: $10.7717 /$ peerj. 7527

Kang, S., Wang, H., Xia, L., Chen, M., Li, L., Cheng, J., Li, X., Jiang, S. (2020). Colorimetric film based on polyvinyl alcohol/okra mucilage polysaccharide incorporated with rose anthocyanins for shrimp freshness monitoring. Carbohyd Polym (229): 115402.

Kant, R., Tabassum, R., Gupta, B. D. (2018). Xanthine oxidase functionalized $\mathrm{Ta}_{2} \mathrm{O}_{5}$ nanostructures as a novel scaffold for highly sensitive SPR based lif optic xanthine sensor. Biosens Bioelectron (99): 637-645.

Kıvrak, E. (2019). Klinik Analizlere Yönelik Aptamer Tabanlı Elektrokimyasal Biyosensör Tasarımı. Ege Üniversitesi Fen Bilimleri Enstitüsü Biyomedikal teknolojiler Anabilim Dalı Yüksek Lisans Tezi, İzmir, Türkiye, 134 s.

Kocaman, N., Sarımehmetoğlu, B. (2010). Gidalarda Akıllı Ambalaj Kullanımı. Vet Hekim Der Derg 81(2): 67-72.
Kuntzler, S. G., Costa, J. A. V., Brizio, A. P. D. R., de Morais, M. G. (2020). Development of a colorimetric $\mathrm{pH}$ indicator using nanofibers containing $\mathrm{T}$ Spirulina sp. LEB 18. Food Chem (328): 126768.

Kuswandi, B., Nurfawaidi, A. (2017). On-package dual sensors label based on $\mathrm{pH}$ indicators for realtime monitoring of beef freshness. Food Control (82): 91-100.

Kürek, M., Hlupic, L., Scetar, M., Bosiljkov, T., Galic, K. (2019). Comparison of two $\mathrm{pH}-$ responsive color-changing bio-based films containing wasted fruit pomace as a source of colorants. J Food Sci, 84(9): 2490-8. doi: 10.1111/1750-3841.14716.

Lafarga, T., Fernandez-Sevilla, J. M., GonzalezLopez, C., Acien-Fernandez, F. G. (2020). Spirulina for the food and functional food industries. Food Res Int (137): 109356.

Latos-Brozio, M., Masek, A. (2020). The application of natural food colorants as indicator substances in $\mathrm{T}$ intelligent biodegradable packaging materials. Food Chem Toxicol (135): 110975.

Lazaro, C.A., Junior, C.A.C., Canto, A.C.V.C.S., Monteiro, M., L., G. (2015). Biogenic amines as bacterial quality indicators in different poultry meat species. LWT- Food Science and Techn (60): 1521.

Lee, K., Baek, S., Kim, D., Seo, J. (2019). A freshness indicator for monitoring chicken-breast spoilage using a Tyvek ${ }^{\circledR} \mathrm{T}$ sheet and RGB color analysis. Food Packaging and Shelf Life (19): 40-46.

Li, Y., Wu, K., Wang, B., Li, X. (2021). Colorimetric indicator based on purple tomato anthocyanins and chitosan for application in intelligent packaging. Int J Biol Macromol (174): 370-376.

Liu, D., Cui, Z., Shang, M., Zhong, Y. (2021). A colorimetric film based on polyvinyl alcohol/sodium carboxymethyl cellulose incorporated with red cabbage anthocyanin for monitoring pork freshness. Food Packaging and Shelf Life (28): 100641. 
Luo, X., Lim, L-T. (2020). Curcumin-loaded electrospun nonwoven as a colorimetric indicator for volatile amines. LWT - Food Science and Technology (128): 109493.

Metin, S., Erkan, N., Varlı, C. (2002). The Application of Hypoxanthine Activity as a Quality Indicator of Cold Stored Fish Burgers. Turk J Vet Anim Sci (26): 363-367.

Miklicanin, E. O., Valzacchi, S. (2017). Development of new chemiluminescence biosensors for determination of biogenic amines in meat. Food Chem (235): 98-103.

Mohammadalinejhad, S., Almasi, H., Moradi, M. (2020). Immobilization of Echium amoenum anthocyanins into bacterial cellulose film: A novel colorimetric $\mathrm{pH}$ indicator for freshness/spoilage monitoring of shrimp. Food Control https://doi.org/10.1016/j.foodcont.2020.10716 9.

Moradi, M., Tajik, H., Almasi, H., Forough, M., Ezati, P. (2019). A novel pH-sensing indicator based on bacterial cellulose nanofibers and black carrot anthocyanins for monitoring fish freshness. Carbohyd Polym (222): 115030.

Moreira, J. B., Terra, A. L. M., Costa, J. A. V., de Morais, M. G. (2018). Development of $\mathrm{pH}$ indicator from PLA/PEO ultrafine fibers containing pigment of microalgae origin. Int J Biol Macromol (118) Part B: 1855-1862.

Mustafa, F., Othman, A., Andeescu, S. (2021). Cerium oxide-based hypoxanthine biosensor for Fish spoilage monitoring. Sensor Actuat B-Chem (332): 129435.

Öksüztepe, G. ve Beyazgül, P. (2015). Ak1llı Ambalajlama Sistemleri ve Gıda Güvenligĭ. F.U: Sag. Bil. Vet. Derg, 29(1): 67 - 74.

Pacquit, A., Lau, K. T., McLaughlin, H., Frisby, J., Quilty, B., \& Diamond, D. (2006). Development of a volatile amine sensor for the monitoring of fish spoilage. Talanta, 69(2): 515-520.

Park, Y. V., Kim, S. M., Lee, J. Y., Jang, W. (2015). Application of biosensors in smart packaging. Mol Cell Toxicol (11): 277-285 Doi: 10.1007/s13273015-0027-1
Purma, Ç., Serdaroğlu, M. (2006). Akillı Ambalajlama Sistemlerinin Gida Sanayiinde Kullanımı. Türkiye 9. Gıda Kongresi, 24-26 Mayıs 2006, Bolu, Türkiye 49-52 s.

Qiao, L., Tang, X., Dong, J. (2017). A feasibility quantification study of total volatile basic nitrogen (TVB-N) content in duck meat for freshness evaluation. Food Chem (237): 1179-1185.

Rajamäki T., Alatomi H., Titvanen T., Skyttä E., Smolander M., Ahvenainen R. (2004). Application of an electronic nose for quality assessment of modified atmosphere packaged poultry meat. Food Control (17): 5-13.

Reza, K.K., Singh, N., Yadav, S.K., Singh, M.K., Biradar, A.M. (2014). Pearl shaped highly sensitive $\mathrm{Mn}_{3} \mathrm{O}_{4}$ nanocomposite interface for biosensor applications. Biosens Bioelectron (62): 4751.

Roy, S., Rhim, J-W. (2020). Anthocyanin food colorant and its application in $\mathrm{pH}$-responsive color change indicator films. Crit Rev Food Sci Nutr. Doi: 10.1080/10408398.2020.1776211.

Saraç, A. (2011). Atatürk Baraj Golu’nde yașayan Carasobarbus luteus ve Capoeta rutta' da balık tazeliginin tespiti. Harran Üniversitesi Fen Bilimleri Enstitüsü Biyoloji Anabilim Dalı Yüksek Lisans Tezi, Şanlıurfa, Türkiye, $56 \mathrm{~s}$.

Sinelli, N., Limbo, S., Torri, L., di Egidio, V., Casiraghi, E. (2010). Evaluation of freshness decay of minced beef stored in high-oxygen modified atmosphere packaged at different temperatures using NIR and MIR spectroscopy. Meat Sci (86): 748-752.

Sujiwo, J., Kim, D., Jang, A. (2018). Relation among quality traits of chicken breast meat during cold storage: Correlations between freshness traits and torrymeter va- lues. Poult Sci (97): 28872894.

Sujiwo, J., Kim, H-J., Song, S-O., Jang, A. (2019). Relationship between quality and freshness traits and torrymeter value of beef loin during cold storage. Meat Sci (149): 120-125.

Şenman, N. H. (2007). Gökkuşağı alabalıklarında (onchornycus mykiss) biyojen aminlerin HPLC ile saptanması. Ankara Üniversitesi Sağlık Bilimleri 
Enstitüsü Besin Hijyeni ve Teknolojisi Anabilim Dalı Yüksek Lisans Tezi, Ankara, Türkiye, 57 s.

Takma, D. K., Nadeem, H. Ş. (2019). Gıdalarda ak1lh ambalajlama teknolojisi ve güncel uygulamalar. GIDA 44(1): 131-142. Doi: 10.15237/gida.GD18106.

Topçu, Ş., Çölgeçen, H. (2015). Bitki sekonder metabolitlerinin biyoreaktölerde üretilmesi. Türk Bilimsel Derlemeler Dergisi, 8(2): 09-29.

Vanegas, D., Patin o, L., Mendez, C., Oliveira, D.A., Torres, A.M., Gomes, C.L., McLamore, E.S. (2018). Laser scribed graphene biosensor for detection of biogenic amines in food samples using locally sourced materials. Biosensors, 8(2): 42.

Verma, N., Hooda, V., Gahlaut, A., Gothwal, A., Hooda, V. (2019). Enzymatic biosensors for the quantification of biogenic amines: a literature update. Crit Rev Biotechnol (40), 2020 - (1): 1-14.

Vo, T.-V., Dang, T.-H., Chen, B.-H. (2019). Synthesis of intelligent $\mathrm{pH}$ indicative films from chitosan/poly(vinyl alcohol)/anthocyanin extracted from red cabbage. Polymers, 11(7): 1088. doi: $10.3390 /$ polym11071088.

Wang, Z., Ma, B., Shen, C., Lai, O., Tan, C., Cheong, L. (2019). Electrochemical Biosensing of Chilled Seafood Freshness by Xanthine Oxidase Immobilized on Copper-Based Metal-Organic Framework Nanolif Film. Food Anal. Methods (12): 1715-1724.

Wei, Y-C., Cheng, C-H., Ho, Y-C., Tsai, M-L., Mi, F-L. (2017). Active gellan gum/purple sweet potato composite films capable of monitoring $\mathrm{pH}$ variations. Food Hydrocoll (69): 491-502.

Werner, T., Klimant, I., Wolfbeis, O.S. (1995). Ammonia-sensitive polymer matrix employing immobilised indicator ion pairs. Analyst (120): 1627-1631.

Wojnowski, W., Majchrzak, T., Dymerski, T., Gebicki, J., Namiesnik, J. (2017). Electronic noses: Powerful tools in meat quality assessment. Meat Sci (131): 119-131.

Wojnowski, W., Namieśnik, J., Płotka-Wasylka, J. (2019). Dispersive liquid-liquid microextraction combined with gas chromatography-mass spectrometry for in situ determination of biogenic amines in meat: Estimation of meat's freshness. Microchem J (145): 130-138.

Wu, C., Li, Y., Sun, J., Lu, Y., Tong, C., Wang, L., Yan, Z., Pang, J. (2020). Novel konjac glucomannan films with oxidized chitin nanocrystals immobilized red cabbage anthocyanins for intelligent food packaging. Food Hydrocoll (98): $105245 . \quad$ Doi: 10.1016/j.foodhyd.2019.105245.

Wu, C., Sun, J., Chen, M., Ge, Y., Ma, J., Hu, Y., Pang, J., Yan, Z. (2019). Effect of oxidized chitin nanocrystals and curcumin into chitosan films for seafood freshness monitoring. Food Hydrocoll (95): 308-317.

Yazdanparast, S., Benvidi, A., Abbasi, S., Rezaeinasab, M. (2019). Enzyme-based ultrasensitive electrochemical biosensor using poly(L-aspartic acid)/MWCNT bionanocomposite for xanthine detection: A meat freshness marker. Microchem J (149): 104000.

Zaragozá, P., Fuentes, A., Fernandez-Segovia, I., Vivancos, J. L., Rizo, A., Ros-Lis, J. V. (2013). Evaluation of sea bream (Sparus aurata) shelf life using an optoelectronic nose. Food Chem 138 (23): 1374-1380.

Zeng, P., Chen, X., Qin, Y., Zhang, Y., Wang, X., Wang, J., Ning, Z., Ruan, Q., Zhang, Y. (2019). Preparation and characterization of a novel colorimetric indicator film based $\mathrm{T}$ on gelatin/polyvinyl alcohol incorporating mulberry anthocyanin extracts for monitoring fish freshness. Food Res. Int. (126): 108604.

Zhai, X., Li, Z., Shi, Y., Huang, X., Sun, Z., Zhang, D., Zou, X., Sun, Y., Zhang, J., Holmes, M., Gong, Y., Povey, M., Wang, S. (2019). A colorimetric hydrogen sulfide sensor based on gellan gum-silver $\mathrm{T}$ nanoparticles bionanocomposite for monitoring of meat spoilage in intelligent packaging. Food Chem (290): 135-143.

Zhai, X., Shi, J., Zou, X., Wang, S., Jiang, C., Zhang, J., Huang, X., Zhang, W., Holmes, W. (2017). Novel colorimetric films based on starch/polyvinyl alcohol incorporated with 
roselle anthocyanins for fish freshness monitoring. Food Hydrocoll (69): 308-317.

Zhai, X., Wang, X., Zhang, J., Yang, Z., Sun, Y., Li, Z., Huang, X., Holmes, M., Gong, Y., Povey, M., Shi, J., Zou, X. (2020b). Extruded low density polyethylene-curcumin film: A hydrophobic ammonia sensor for intelligent food packaging. Food Packaging and Shelf Life (26): 100595.

Zhai, X., Zou, X., Shi, J., Huang, X., Sun, Z., Li, Z., Sun, Y., Li, Y., Wang, X., Holmes, M., Gong, Y., Povey, M., Xiao, J. (2020a). Amine-responsive bilayer films with improved illumination stability and $\mathrm{T}$ electrochemical writing property for visual monitoring of meat spoilage. Sensor Actuat B-Chem (302): 127130.

Zhang, J., Huang, X., Shi, J., Liu, L., Zhang, X., Zou, X., Xiao, J., Zhai, X., Zhang, D., Li, Y., Shen, T. (2021). A visual bi-layer indicator based on roselle anthocyanins with high hydrophobic property for monitoring griskin freshness. Food Chem (355): 129573.

Zhang, J., Huang, X., Zou, X., Shi, J., Zhai, X., Liu, L., Li, Z., Holmes, M., Gong, Y., Povey, M., Xiao, J. (2021). A visual indicator based on curcumin with high stability for monitoring the freshness of freshwater shrimp, Macrobrachium rosenbergii. J. Food Eng. (292): 110290.

Zohora, S.E., Khan, A.M., Srivastava, A.K., Hundewale, N. (2013). Electronic noses application to food analysis using metal oxide sensors: a review. Int. J. Soft Comput. Eng. (3): 199_ 205. 